the depth of the wave path. Should this be so, the next suggeition is, that as a wave proceeds downwards refraction may take place, and that a focal concentration of energy may be found at the antipodes of a seismic centre.

From these remarks it is clear that amongst the most important work with which the seismologist has now before him, is to measure the speed at which the preliminary vibrations of an earthquake are transmitted, and because this is high, the definition on the recording surface must be clear, the rate at which this is moved must be such that time intervals may be measured to within ro seconds, and the observing stations, if they are limited in number, should be widely separated.

In the choice of stations, at all of which there must be the means of keeping fairly accurate time, the plan originally suggested by the author was to choose these relatively to districts where large earthquakes are frequent. The districts selected were the South American coast, Japan, and the Philippines, Himalaya and Central Asia. By a system of trials it was found that fifteen stations could be chosen, nearly all of which happen to be in the United States or British colonies, about ten of which would form a series approximately 2000 miles and multiples of 2000 miles distant from any of the three districts.

With a series of this description, data of a fairly complete nature respecting the rate at which motion may be transmitted round and, possibly, through our earth at varying depth should be obtainable. Any addition to this series would naturally render our information more certain, and add to the value of records obtained from centres other than those specified.

The cost of installation at each observatory would be approximately $£ 50$

The proposal here made is similar to one published by the writer in January 1895, and does not materially differ from the one put forward by that distinguished investigator, the late Dr. E. von Rebeur-Paschwitz, and now being so warmly advocated by Dr. G. Gerland of Strassburg (see pp. I35, I36).

J. M.

\section{THE SPECIFIC GRAVITY OF THE WATERS OF THE SEA.}

I $\mathrm{N}$ continuation of his paper on oceanic circulation, in the concluding volume of the Challenger Reports, which chiefly dealt with the distribution of temperature, Dr. Buchan has published in the Transactions of the Royal Society of Edinburgh a series of maps showing, so far as the present state of knowledge permits, the specific gravity of the waters of the great oceans at various depths; and accompanying the maps is an extended discussion of some of the points treated in the previous memoir.

In the paper just published, Dr. Buchan has departed from the mode of representing salinities and specific gravities employed in the Challenger Report, and instead of charting the actual values, gives the departures above and below an average assumed to be a mean for all the oceans. It is difficult to see that anything is gained by this method; and it has the undoubted disadvantage that any future change in the assumed means will involve the reconstruction of all the maps. Even at the surface there are considerable portions of the sea of which we can only guess at the *mean temperature and salinity, and the general average given by Dr. Buchan may therefore undergo modification, notwithstanding the attempts to apply a process of integration. Below the surface, the general average is simply the mean of existing observations; and while an inspection of the map shows that these are by no means perfect, the fact that there is only a single line of observations in the North Pacific, one in the Southern Ocean, none in the Atlantic north of $40^{\circ}$, and none in the Indian Ocean, indicates that the general averages must be mere approximations. Another unsatisfactory effect of the adoption of this method is due to the fact that values above and below the general average are thrown into strong contrast by being printed in different colours on the maps, thereby frequently exaggerating their apparent difference. In the case of the North Pacific, for example, Dr. Buchan lays great stress on the low specific gravity of the waters of this ocean at all depths. Undoubtedly the observations show that they are lighter than the Atlantic by a quantity amounting below the surface to about 0.0008 ; but the fact remains that a change of, say, 0003 in the mean for the globe at 300 fathoms would throw the whole of the North Pacific above the average, while the observations within that area themselves show inconsistencies amounting to double that quantity. We draw special attention to this point, because it seems to lie at the root of a certain weakness in the line of argument taken up by Dr. Buchan, leading to a confusion of what we may call the statical and dynamical problems of ocean circulation, somewhat analogous to that involved in Ferrel's theory of cyclones. In drawing up any general scheme of the movements of oceanic waters, it is necessary to keep clearly in mind certain "conditions of continuity"; if the surface salinity is anywhere reduced by copious rainfall, it must somewhere else be correspondingly increased by evaporation; if reduced by melting of field ice, a corresponding quantity of salt must have been added to the deeper waters where the ice was formed; if up-welling is produced by an off-shore wind, the same force must be competent to cause a down.draught somewhere else. These considerations seem to suggest several simplifications in the scheme of circulation proposed by Dr. Buchan.

Comparing the Atlantic and Pacific Oceans, we find in the former a limited area subject to atmospheric systems of considerable intensity, the air over a considerable proportion of the surface being relatively dry. Over the Atlantic there is accordingly a relatively great amount of evaporation, producing high surface salinity, and the water carried off is distributed over an area nearly four times as large as in the case of the Pacific, allowing of its gradual return. In the Pacific, on the other hand, the winds are not so strong, the rate of evaporation is slower, and the redistribution of the moisture more local. It may therefore be possible to account for a considerable part of the low salinity of the Pacific without assuming that the high rainfall of the East Indian region produces effects so markedly in excess of those due to the immense discharges of fresh water into the Atlantic or the Indian Ocean. Dr. Schott's observations in East Indian waters support this view, indicating that the great treshening due to heavy rainfall is here, as elsewhere, largely restricted to the immediate neighbourhnod of the land.

As an example of the converse of the foregoing, we may take the case of the undercurrent flowing from the Mediterranean to the Atlantic through the Straits of Gibraltar. From the observations of temperature and salinity Dr. Buchan regards it as placed "beyond dispute" that the warming effect of this outflowing water " becomes strikingly apparent at about 500 fathoms," and "beyond this depth its influence is felt over nearly the whole breadth of the Atlantic to at least about 1000 fathoms." Now at the Straits of Gibraltar the depth is something under 200 fathoms, and the extreme width at the surface a little greater than the Straits of Dover; and it is known that the loss by evaporation from the surface of the Mediterranean is not nearly compensated for by the fresh water additions from the rainfall and the rivers which empty themselves into its basin. The amount of water issuing into the Atlantic must therefore be greatly less than the amount entering the Mediterranean, and a comparison of the volumes and temperatures of the two bodies of water shows that it is almost impossible to give the outflow from the Mediterranean credit for such widespread action.

The two cases we have quoted, perhaps the strongest of several suggested by Dr. Buchan's papers, seem to support the results of a number of recent investigations, indicating that the effect of differences of specific gravity, while by no means a negligible quantity, is in general small compared to the dynamical effects due to the momentum of the surface currents, even at great depths.

From this point of view, we at once obtain help from the researches of Pettersson and Kriimmel, noting specially their results as to the tendency of surface currents to induce reaction currents under them, and to divide on changing dir.ction, and bearing in mind the deflecting influence of the earth's rotation at all depths. In the Atlantic, the water driven northward along the American coast is blocked by the land, and is partly drained off by the easterly drift currents, partly sent downwards in a column separated into two parts, at least in certain seasons, by a bulging out of the cold Labrador current. Crossing towards the west coast of Europe, the easterly drift divides, a part escaping northward under regulation of the polar streams from the east of Greenland and Iceland, and a part banking up against the French and Spanish coasts and the north-west of Africa, as is shown by the "bottle charts" of the Prince of Monaco and M. Hautreux. The shape of the coast prevents all the water escaping laterally, and a part descends, carrying with it the efflux from the Mediterranean.

In the Pacific the effect is similar, subject to the difference that while the circulation is less energetic, it is also less inter-

NO. I 393, VOL. 54] 
fered with by the configuration of the land, and except off the coast of Central America, where the south-easterly drift is again "cornered," the effect of the earth's rotation becomes more apparent. The difference due to the Pacific being closed at its northern extremity is extremely striking.

\section{H. N. Dickson.}

\section{THE UNIVERSITY OF LONDON.}

$\mathrm{O}^{\mathrm{N}}$ Monday the Duke of Devonshire introduced a Bill in the House of Lords to make further provision with respect to the University of London. In the course of a brief statement as to the circumstances which have led to the introduction of the Billthe Duke of Devonshire explained that the Cowper Com, mission reported two years ago in favour of London University being made a teaching as well as an examining University, and recommended the appointment of a Statutory Commission to carry out the details of the scheme. It will be remembered that a Bill dealing with the question was introduced by Lord Playfair in the last Session of the late Parliament, but it was not proceeded with in consequence of the dissolution. His Lordship is reported by the Times to have said : "I believe that neither University College nor King's College is altogether satisfied with the scheme as sketched out in the Commissioners' report. But still more formidable opposition has manifested itself, not on the part of Convocation of London University as formally constituted, but on the part of a considerable body of members of Convocation residing for the most part in the provinces. This opposition, I believe, proceeds from an apprehension that under the proposed constitution of the University the teachers of the affiliated institutions and colleges will exercise a large and perhaps undue influence over the examinations of the University, and that students who have prosecuted their studies in independent colleges or privately will in future be placed at some disadvantage. The apprehension is that either the high standard which, it is admitted, has always been maintained by the London University will be lowered, or else that in the examinations arranged by the new body external students will compete on unfair terms as compared with students in the recognised teaching institutions. To meet objections of this kind we give in this Bill a somewhat wider discretion and larger powers to the proposed Statutory Commission than were proposed to be given in the Bill presented by Lord Playfair last year. While the Commissioners will be directed, as in the Bill of last year, to proceed upon the proposals of the late Royal Commission, they will also be directed to inquire into and have regard to the requirements of both the internal and external students. I trust that an opportunity will be afforded, by presenting this
measure in a definite shape, to those who are concerned of ascertaining the real character of any opposition which may be offered to the proposed change in the constitution of the London University. Personally I am insensible to the motives which have actuated some graduates in offering considerable opposition to those proposals. After all it is the Senate of the London University which is charged with the duty, and on which rests the responsibility of watching over the interests and upholding the character of the University, and this Bill and the proposals of the Commission which it seeks to carry into effect have, I am assured, the warm approval of a large majority of the Senate of the University of London. This is a measure which practically has been recommended by two Royal Commissions, each of which was composed of men highly competent to pronounce an opinion on such a question as this. It is, I believe, supported by a very large majority of the most eminent scientific and educational authorities in the country, and it is, in my opinion, a very great anomaly, almost approaching to a scandal, that the great City of London should alone of all the great cities in the United Kingdom-and I believe I may add alone among the great cities of Europe-have remained up to this time without a teaching University. The experience during the last ten years of abortive attempts-which I have briefly recounted to your lordships-shows that almost insuperable difficulties exist to the establishment of any such teaching University in any other way than that which has been proposed by the late Royal Commission. It has been almost conclusively proved that the intervention of Parliament through the appointment of a Statutory Commission is necessary, and is the only means by which this desirable end can be effected." The Bill was then read a first time.

$$
\text { NO. I 393, VOL. } 547
$$

\section{UNIVERSITY AND EDUCATIONAL INTELLIGENCE.}

THE French Senate has adopted the Bill for the establishment of district universities.

THE archrological library of the Ashmolean Museum at Oxford was struck by lightning during a severe storm on Tuesday, and the roof was set on fire, but fortunately the valuable books in the library were not damaged.

Dr. J. Norman Collie, F.R.S., Assistant Professor of Chemistry at University College, London, has been appointed Professor of Chemistry in the Pharmaceutical Society's School of Pharmacy.

IN answer to a question put by Colonel Lockwood in the House of Commons, the Vice-President of the Council said, some nights ago, that the Teachers' Registration Bill could, as far as he could see, only be proceeded with this session if it were made entirely non-contentious.

LORv Cross, Master of the Worshipful Company of Clothworkers, on Friday will lay the foundation-stone of a research laboratory in connection with the dyeing department of the Yorkshire College, Leeds. The expense of the new buildings, $\mathcal{E}_{15}, 000$, is being borne by the Clothworkers' Company.

THE arrangements for the transfer of the right of patronage to the chair of Natural History in the University of Edinburgh, now exercised by the Crown, to the curators of patronage in the University, and the transfer of the right of patronage to the chair of Botany, now vested in the curators to the Crown, have been incorporated in a Bill, and the Bill has been introduced into the House of Lords by the Government.

AT the annual summer meeting of the Incorporated Association of Head Masters, which was opened on Friday last at Leicester, it was moved: "That to ensure the proper organisation of secondary education it is essential that, with the exception of non-local schools, every school or department of a school providing secondary education should be placed under a county authority administering secondary education." It was further agreed that the "local authority for secondary education should in no case administer a smaller area than that of an administrative county as defined by the Local Government Board."

REFERRING to the cost of education in Switzerland, Her Majesty's Secretary of Legation at Berne points out that it is much less than in England. In I 893 there were 8390 primary schools in Switzerland, with 469,800 children, and an average of 50 pupils per teacher, of whom there were 6290 masters and 3180 mistresses. The expenses of the cantons were, on an average, 50 francs $(£ 2)$ per pupil, or 8 francs $(6 s .8 d$.) per inhabitant. In the Polytechnic School of Ziirich, to which the Federal Government makes an annual grant of $£ 36,800$, there are 720 pupils, of whom 309 are foreigners. Instruction is given in architecture, civil engineering, mechanics, chemistry, forestry, and training of teachers. The fees are about $£ 8$ Ios. per pupil. There are commercial schools in six cantons, where the average expense to the pupil is $£$ I 8 IOs. per head. There are seven universities, with a total of 3742 male and $49 \mathrm{I}$ female students in theology, law, medicine, dc., among whom are many foreigners. There are, moreover, technical schools of all sorts for instruction in farming, dairy work, vine culture, \&c., established throughout the country. In 1893, in the twenty-five cantons of the confederation, the expenses on account of education were, by the State, $£ 660,200$, and by the communes $£ 839,960$, making a total of $£ \mathrm{I}, 500, \mathrm{I} 60$, or an average of about IOs. per inhabitant. Under the heading of technical instruction $£ \mathrm{I}, 575,000$ was spent in $\mathrm{I} 894$.

The Committee of Council on Education have decided to modify the existing rules for grants for instruction in science and in art, contained in the Science and Art Directory and the Minute of August 2I, I895, as follows, except as regards organised science schools and training colleges, to which these alterations do not apply :--In place of payments on the results of examination an attendance grant, except as stated below, will be made, on the certificate of the Committee of the 